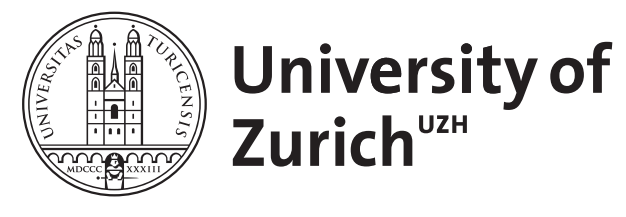

\title{
Porphyromonas gingivalis induces RANKL in T-cells
}

Belibasakis, G N ; Bostanci, N ; Reddi, D

\begin{abstract}
Porphyromonas gingivalis is an oral pathogen highly implicated in chronic periodontitis, a disease characterized by inflammatory destruction of the tooth-supporting alveolar bone and eventually, tooth loss. T-cell innate immune responses are actively involved in this pathological process. Receptor activator of NF-kappaB Ligand (RANKL) is a cytokine that stimulates bone resorption, while its soluble decoy receptor osteoprotegerin (OPG) blocks its action. This study aimed to investigate in Jurkat T-cells the effects of $\mathrm{P}$. gingivalis on the RANKL-OPG system and the major inflammatory mediator of bone resorption prostaglandin $\mathrm{E}(2)(\mathrm{PGE}(2))$. P. gingivalis caused concentration-dependent up-regulation of RANKL gene expression and protein production, assessed by quantitative PCR and ELISA, respectively. PGE(2) production was also enhanced. However, OPG was not detected. In conclusion, P. gingivalis induces RANKL and PGE(2) in T-cells, potentially favoring bone resorption. These T-cell responses to $\mathrm{P}$. gingivalis may contribute to the pathogenesis of inflammatory alveolar bone destruction occurring in chronic periodontitis.
\end{abstract}

DOI: https://doi.org/10.1007/s10753-010-9216-1

Posted at the Zurich Open Repository and Archive, University of Zurich ZORA URL: https://doi.org/10.5167/uzh-42993

Journal Article

Published Version

Originally published at:

Belibasakis, G N; Bostanci, N; Reddi, D (2011). Porphyromonas gingivalis induces RANKL in T-cells. Inflammation, 34(2):133-138.

DOI: https://doi.org/10.1007/s10753-010-9216-1 


\title{
Porphyromonas gingivalis Induces RANKL in T-cells
}

\author{
Georgios N. Belibasakis, ${ }^{1,3}$ Durga Reddi, ${ }^{2}$ and Nagihan Bostanci ${ }^{1}$
}

\begin{abstract}
Porphyromonas gingivalis is an oral pathogen highly implicated in chronic periodontitis, a disease characterized by inflammatory destruction of the tooth-supporting alveolar bone and eventually, tooth loss. T-cell innate immune responses are actively involved in this pathological process. Receptor activator of NF-KB Ligand (RANKL) is a cytokine that stimulates bone resorption, while its soluble decoy receptor osteoprotegerin (OPG) blocks its action. This study aimed to investigate in Jurkat T-cells the effects of $P$. gingivalis on the RANKL-OPG system and the major inflammatory mediator of bone resorption prostaglandin $\mathrm{E}_{2}\left(\mathrm{PGE}_{2}\right)$. P. gingivalis caused concentration-dependent up-regulation of RANKL gene expression and protein production, assessed by quantitative PCR and ELISA, respectively. $\mathrm{PGE}_{2}$ production was also enhanced. However, OPG was not detected. In conclusion, $P$. gingivalis induces RANKL and $\mathrm{PGE}_{2}$ in T-cells, potentially favoring bone resorption. These T-cell responses to $P$. gingivalis may contribute to the pathogenesis of inflammatory alveolar bone destruction occurring in chronic periodontitis.
\end{abstract}

KEY WORDS: Porphyromonas gingivalis; RANKL-OPG system; T-cells; $\mathrm{PGE}_{2}$; periodontitis.

\section{INTRODUCTION}

Periodontal disease is potentially the most common inflammatory disease of infectious etiology in humans. It is characterized by the destruction of the tooth-supporting (periodontal) tissues, ultimately resulting in tooth loss. Porphyromonas gingivalis is a Gram-negative black-pigmenting anaerobe, highly implicated in human chronic periodontitis [1]. In vivo studies have also demonstrated that $P$. gingivalis can induce periodontitis in experimental animal models [2]. It is postulated that this oral pathogen can perturb the local immunity and deregulate the host inflammatory responses in the periodontal tissues, properties attributed to its virulence factors [3-5]. Due to these properties, $P$. gingivalis may

\footnotetext{
${ }^{1}$ Institute of Oral Biology, Center of Dental and Oral Medicine and Cranio-Maxillofacial Surgery, University of Zürich, Plattenstrasse 11, 8032, Zürich, Switzerland

2 Institute of Dentistry, Barts and the London Queen Mary's School of Medicine and Dentistry, London, UK

${ }^{3}$ To whom correspondence should be addressed at Oral Microbiology and Immunology, Institute of Oral Biology, Center of Dental and Oral Medicine and Cranio-Maxillofacial Surgery, University of Zürich, Plattenstrasse 11, 8032, Zürich, Switzerland. E-mail: george. belibasakis@zzmk.uzh.ch
}

invade into the deeper periodontal tissues [6] and establish chronic inflammation.

The pathogenesis of periodontitis involves the destruction of the tooth-supporting alveolar bone as a result of the inflammation triggered by oral bacteria. Early observations have outlined that the presence of lymphocytes in the inflammatory infiltrate of histopathological lesions of periodontitis [7]. It is now well established that T-cells, have a key role in the pathogenesis of periodontal disease, particularly by mediating the resorption of the alveolar bone $[8,9]$. The notion that CD4+ Th1 cells are central to the cell-mediated immunity events associated with the disease, particularly through interferon- $\gamma$ production, is now challenged by the discovery of the interleukin-17-producing Th17 population [10]. Although it has been proposed that Th17 cells confer specific osteoclast-inducing activity [11], their precise role in periodontitis is still unclear. On the molecular level, the process of bone resorption is determined by the interplay of members of the tumor necrosis factor (TNF) ligand and receptor families [12]. Receptor activator of NF- $\mathrm{KB}$ ligand (RANKL), a member of the TNF ligand family, is expressed as cell surface-associated or secreted ligand by osteoblasts, periodontal fibroblasts, as well as activated $\mathrm{T}$ - and B- 
cells [13]. RANKL expression can be induced by several systemic hormones and local inflammatory mediators, such as prostaglandin $\mathrm{E}_{2}\left(\mathrm{PGE}_{2}\right)$ [14]. RANKL activates its cognate receptor activator of NF-KB (RANK) receptor on monocytic precursors, triggering their differentiation into multinucleated bone-resorbing osteoclasts. Osteoprotegerin (OPG) is a soluble decoy receptor for RANKL that inhibits its interaction with RANK, thus preventing osteoclastogenesis and bone resorption [15]. The importance of these molecules in periodontal diseases has been demonstrated in clinical investigations $[16,17]$.

Recent work has demonstrated that $P$. gingivalis up-regulates RANKL and down-regulates OPG expression in gingival fibroblasts and periodontal ligament cells [18], as well as bone marrow stromal cells [19]. $\mathrm{PGE}_{2}$ is considered a potential mediator of $P$. gingivalisinduced RANKL expression [19-21]. It is also well established that $P$. gingivalis is a potent inducer of T-cell responses $[22,23]$. These responses appear to mediate alveolar bone loss in related experimental periodontitis model $[24,25]$. However, there is as yet no evidence on the potential effects of $P$. gingivalis on the regulation of the RANKL-OPG system in T-cells. This information would provide additional mechanistic insights to the role of $P$. gingivalis in bone resorption occurring in periodontitis. Therefore, the aim of this study was to investigate the effect of $P$. gingivalis on RANKL and OPG gene expression and protein secretion, as well as $\mathrm{PGE}_{2}$ production, in a human Tcell line.

\section{MATERIALS AND METHODS}

\section{Cell Cultures}

Jurkat T-lymphocyte leukemia cells (E6-1; American Type Tissue Culture Collection) were used in this study. The cells were maintained in RPMI Glutamax (Gibco BRL Life Technologies) supplemented with 10\% fetal bovine serum. The cells were cultured in suspension at a density of $10^{6}$ cells $/ \mathrm{ml}$. For the experiments, the cells were cultured in the presence or absence of ascending protein concentrations of $P$. gingivalis culture supernatants for $6 \mathrm{~h}$.

\section{Bacterial Cultures and Growth Conditions}

$P$. gingivalis W50 wild-type strain was cultured on blood agar base supplemented with $5 \%$ horse blood (Oxoid) and maintained by weekly subculture for up to
5 weeks. Liquid cultures were prepared by inoculation of bacterial colonies (3-4 days old) from blood agar plates into $10 \mathrm{ml}$ brain heart infusion broth (Oxoid) supplemented with $5 \mathrm{mg} / \mathrm{l}$ hemin (Sigma), and incubated for $24 \mathrm{~h}$. Ten percent inoculum was transferred to $90 \mathrm{ml}$ of the same medium and incubated for 6 days. All cultures were grown at $37^{\circ} \mathrm{C}$ in a Don Whitley anaerobic cabinet, MACS MG500, in an atmosphere of $80 \% \mathrm{~N}_{2}, 10 \% \mathrm{H}_{2}$, and $10 \% \mathrm{CO}_{2}$. After this culture period, bacteria were harvested by centrifugation at $10,000 \times g$ for $15 \mathrm{~min}$ at $4^{\circ} \mathrm{C}$ and supernatants were collected, filter-sterilized over a $0.2 \mu \mathrm{m}$ filter, and stored at $-80^{\circ} \mathrm{C}$ until use. Protein concentration of these $P$. gingivalis preparations was determined by Bio-Rad Protein assay (Bio-Rad). For the experiments, these culture supernatants were diluted in the cell culture medium. Their final concentration in the experimental cell cultures was expressed in microgram per milliliter.

\section{Extraction of Total RNA and Synthesis of cDNA}

Upon termination of the experiments, total RNA was extracted from the cells using RNeasy Mini kit (QIAGEN) according to the manufacturer's instructions. RNA was quantified using a nanodrop spectrophotrometer and reversed transcribed into cDNA. One microgram of total RNA was incubated with $0.5 \mu \mathrm{g} / \mathrm{ml}$ of oligo dT primer (Promega) at $70^{\circ} \mathrm{C}$ for $5 \mathrm{~min}$ and cooled on ice. A master mix was added to samples, comprising of $10 \mathrm{mM}$ dNTPs, 200 units of moloney murine leukemia virus reverse-transcriptase enzyme and buffer (Promega), and $\mathrm{dH}_{2} 0$ to a final volume of $25 \mu$ l. For the reverse-transcription reaction, these samples were incubated at $40^{\circ} \mathrm{C}$ for $60 \mathrm{~min}, 70^{\circ} \mathrm{C}$ for $15 \mathrm{~min}$ and cooled down to $4^{\circ} \mathrm{C}$.

\section{Quantitative Real-time Polymerase Chain Reaction (qPCR)}

The quantification of RANKL and OPG mRNA expression was performed by TaqMan ${ }^{\circledR}$ qPCR analysis using an ABI Prism 7900 HT Sequence Detection System and software (Applied Biosystems). For the amplification reactions, a qPCR master mix was used (Abgene). The amplification conditions were $10 \mathrm{~min}$ at $95^{\circ} \mathrm{C}$, followed by 40 cycles at $95^{\circ} \mathrm{C}$ for $15 \mathrm{~s}$ and $60^{\circ} \mathrm{C}$ for $1 \mathrm{~min}$. The Gene Expression Assay (Applied Biosystems) IDs were: RANKL: Hs00243522-m1, OPG: Hs00171068-m1, GAPDH: Hs99999905-m1, and ubiquitin $\mathrm{C}$ (UBC): Hs01871556-m1. The relative expression levels of RANKL and OPG transcripts were 
calculated by using the comparative $\Delta \mathrm{Ct}$ method $\left(2^{-\Delta \mathrm{Ct}}\right.$ formula), after normalization to the average $\mathrm{Ct}$ values of housekeeping genes UBC and GAPDH.

\section{Quantification of RANKL, OPG and PGE 2 Levels by Enzyme-linked Immunosorbent Assay (ELISA)}

Upon termination of the experiments, the Jurkat Tcell cultures in suspension were centrifuged at $1,000 \mathrm{rpm}$ for $5 \mathrm{~min}$. The resulting supernatants were collected for further analysis. Commercially available human-specific ELISA kits were used to quantify RANKL (Immundiagnostik), OPG (Biomedica), and $\mathrm{PGE}_{2}$ (Parameter, $\mathrm{R} \& \mathrm{D}$ Systems) in these culture supernatants.

\section{Statistical Analysis}

The significance of differences between control and test groups was assessed by one-way analysis of variance, and Bonferroni post hoc test. $P$ values $<0.05$ were considered indicative of statistical significance.

\section{RESULTS}

Jurkat T-cells were challenged with ascending protein concentrations of $P$. gingivalis. Concentrations equal or lower than $6.4 \mu \mathrm{g} / \mathrm{ml}$ were used, as these did not elicit any cytotoxic effects as previously determined [26]. The effect on RANKL regulation was first investigated. The qPCR results indicate that $P$. gingivalis caused a concentration-dependent up-regulation of RANKL mRNA expression after a 6-h challenge period (Fig. 1). The highest $P$. gingivalis concentration $(6.4 \mu \mathrm{g} /$ $\mathrm{ml}$ ) caused a 3.7-fold up-regulation of RANKL mRNA expression, compared to the control. Further on, ELISA analysis revealed that RANKL protein secretion was concomitantly increased in the cell culture supernatants, in a concentration-dependent manner (Fig. 2). Compared to the control, RANKL protein levels were increased by 2.2-fold with the highest $P$. gingivalis concentration used.

The effect of $P$. gingivalis on the regulation of OPG, the inhibitor of RANKL, was also investigated in the present experimental systems. However, neither OPG mRNA expression, nor OPG protein secretion were detected in the cell cultures under these conditions, irrespective of the presence or absence of $P$. gingivalis challenge.

Finally, the effect of $P$. gingivalis on $\mathrm{PGE}_{2}$ production was also investigated. The secreted $\mathrm{PGE}_{2}$

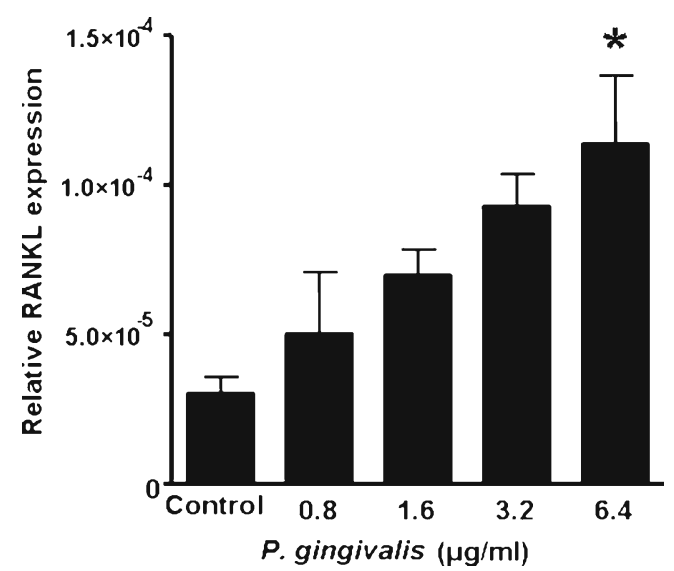

Fig. 1. Effect of $P$. gingivalis on RANKL mRNA expression in Jurkat T-cells. The cells were challenged with ascending protein concentrations of $P$. gingivalis culture supernatants for $6 \mathrm{~h}$. The mRNA expression levels of RANKL were measured by quantitative real-time PCR normalized against the expression levels of the housekeeping genes. The results are expressed as the $2^{-\Delta \mathrm{Ct}}$ formula. Bars mean values \pm SEM from three independent experiments; asterisk statistically significant difference compared to the control group.

levels in the cell culture supernatants were measured by ELISA. After $6 \mathrm{~h}$ of challenge, $P$. gingivalis enhanced $\mathrm{PGE}_{2}$ secretion in a concentration-dependent manner (Fig. 3). The highest concentration of $P$. gingivalis used caused a 2.1-fold up-regulation, compared to the control.

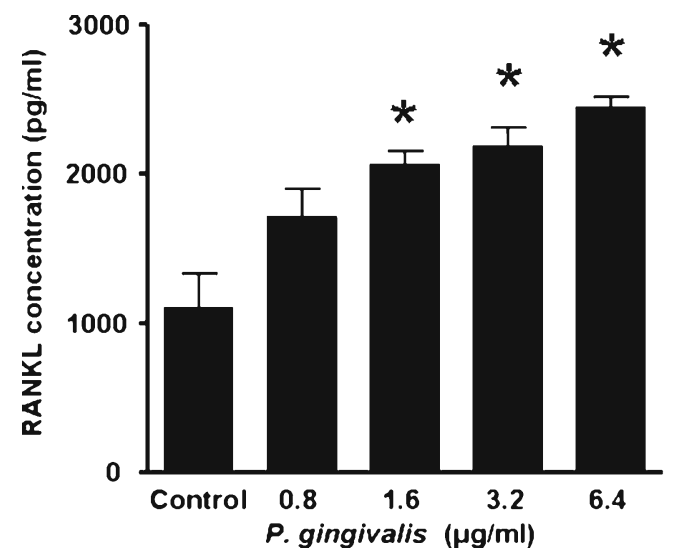

Fig. 2. Effect of $P$. gingivalis on RANKL protein secretion by Jurkat T-cells. The cells were challenged with ascending protein concentrations of $P$. gingivalis culture supernatants for $6 \mathrm{~h}$. The concentrations of RANKL protein secreted into the culture supernatants were quantified by ELISA. The results are expressed as concentration detected in the cell culture supernatant (picogram per milliliter). Bars mean values \pm SEM from three independent experiments: asterisk statistically significant differences compared to the control group. 


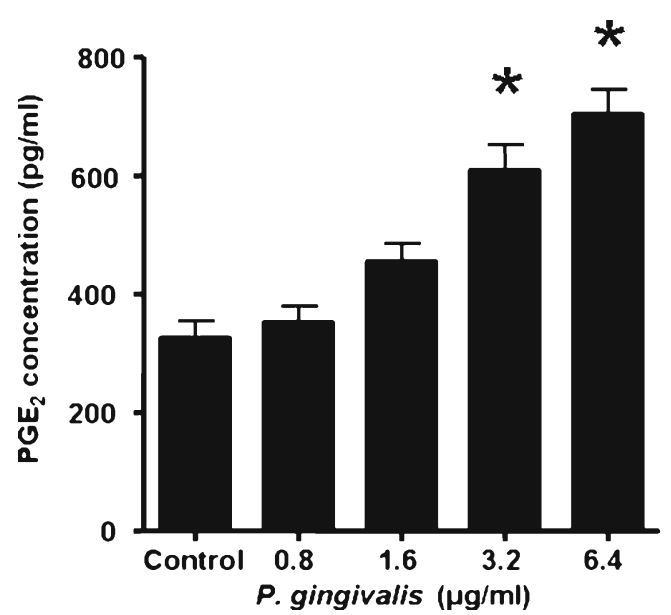

Fig. 3. Effect of $P$. gingivalis on $\mathrm{PGE}_{2}$ production by Jurkat T-cells. The cells were challenged with ascending protein concentrations of $P$. gingivalis culture supernatants for $6 \mathrm{~h}$. The concentrations of $\mathrm{PGE}_{2}$ secreted into the culture supernatants were quantified by ELISA. The results are expressed as concentration detected in the culture supernatant (picogram per milliliter). Bars mean values \pm SEM from three independent experiments; asterisk statistically significant differences compared to the control group.

\section{DISCUSSION}

The present in vitro study has investigated the effect of $P$. gingivalis on the regulation of the RANKLOPG system in the Jurkat T-cells. The results indicate that $P$. gingivalis induces RANKL gene expression, with concomitant RANKL protein production by T-cells. This is in line with previous studies demonstrating that $P$. gingivalis induces RANKL expression in gingival and periodontal ligament fibroblasts [18], as well as bone marrow stromal cells [19]. Therefore, the present finding confirms that T-cells are also responsive to $P$. gingivalis in terms of RANKL induction, among other cell types. Although in this experimental system the magnitude of RANKL induction appears to be modest, this osteoimmunologic response is not trivial. It is an important addition to the current knowledge on the mechanisms of pathogenesis of periodontitis as it may provide a molecular insight to the T-cell mediated responses of $P$. gingivalis in alveolar bone resorption [24]. It is also interesting to note that Jurkat T-cells produce TNF- $\alpha$ converting enzyme (TACE) in response to $P$. gingivalis challenge [26]. TACE is a metalloprotease able to shed RANKL from the cell membrane surface, thus facilitating its release into the immediate extracellular environment and propagating its action [27].
The regulation of OPG was also investigated in the present experimental system. However, OPG expression was not detected in these cells and $P$. gingivalis challenge was not able to induce its expression. The lack of capacity by Jurkat T-cells to express OPG even in response bacterial challenge has previously been demonstrated [28], although it has also been reported that normal CD4+ T-cells can produce OPG [29]. This is an interesting point, as T-cell infiltrates in active periodontal lesions could stimulate bone resorption via RANKL, but it is not clear if they would be able to restore the physiological balance by compensatory OPG production that would inhibit osteoclastogenesis. This could potentially be contributed by the resident periodontal connective tissue cells.

It is known that $\mathrm{PGE}_{2}$ has a major role in the regulation of bone resorption [30], with strong implication in periodontitis [31, 32]. One of the main mechanisms by which $\mathrm{PGE}_{2}$ is involved in bone resorption is by triggering RANKL expression by a variety of cells, and therefore activating the downstream events that lead to osteoclast formation and activation [14]. Among other cells, Jurkat T-cells are also known to produce $\mathrm{PGE}_{2}$ [33-35]. It has been shown that $P$. gingivalis can induce $\mathrm{PGE}_{2}$ production in a variety of cell types, including gingival fibroblasts [36], epithelial cells, and macrophages [37], osteoblasts [20], bone marrow stromal cells [19], as well as whole blood cells [38]. The present study demonstrates that $P$. gingivalis enhances $\mathrm{PGE}_{2}$ production in Jurkat T-cells as well, concomitantly to RANKL. This corroborates previous studies showing that $\mathrm{PGE}_{2}$ is a potential mediator of RANKL induction by $P$. gingivalis [19-21], although this remains to be proven in the present experimental system as well.

In conclusion, the present study demonstrates that $P$. gingivalis induces RANKL, but not OPG expression in Jurkat T-cells. The production of the key inflammatory mediator of bone resorption $\mathrm{PGE}_{2}$ is also enhanced in this experimental system. This indicates that $P$. gingivalis regulates $\mathrm{T}$-cell function in a manner that favors osteoclastogenesis and bone resorption. These observations provide a further mechanistic insight on the role of T-cells in the pathogenesis of periodontal disease, particularly in forms that $P$. gingivalis is involved, such as chronic periodontitis.

Periodontal connective tissue cells and T-cells appear to exhibit differential RANKL and OPG expressions. The former are resident cells that constitutively express OPG, but not RANKL, unless they are bacte- 
rially challenged [18]. This denotes a role in maintaining periodontal homeostasis, but also in contributing to periodontal pathogenesis. On the contrary, T-cells are found in restricted numbers in the healthy periodontium, but are abundant in the disease. Therefore, enhanced RANKL expression by these cells when present in the periodontium may be detrimental for the development of periodontitis.

\section{ACKNOWLEDGMENTS}

This study was supported by the authors' institutes. The authors would like to thank Prof. Michael Curtis (The Blizard Institute of Cell and Molecular Science, Barts and the London School of Medicine and Dentistry) for providing the $P$. gingivalis strain.

\section{REFERENCES}

1. Slots, J., L. Bragd, M. Wikstrom, and G. Dahlen. 1986. The occurrence of Actinobacillus actinomycetemcomitans, Bacteroides gingivalis and Bacteroides intermedius in destructive periodontal disease in adults. J Clin Periodontol 13: 570-577.

2. Genco, R.J., A.W. Ho, J. Kopman, S.G. Grossi, R.G. Dunford, and L.A. Tedesco. 1998. Models to evaluate the role of stress in periodontal disease. Ann Periodontol 3: 288-302.

3. Dixon, D.R., and R.P. Darveau. 2005. Lipopolysaccharide heterogeneity: innate host responses to bacterial modification of lipid a structure. J Dent Res 84: 584-595.

4. Curtis, M.A., J. Aduse-Opoku, and M. Rangarajan. 2001. Cysteine proteases of Porphyromonas gingivalis. Crit Rev Oral Biol Med 12: $192-216$

5. Bostanci, N., R.P. Allaker, G.N. Belibasakis, M. Rangarajan, M.A. Curtis, F.J. Hughes, and I.J. McKay. 2007. Porphyromonas gingivalis antagonises Campylobacter rectus induced cytokine production by human monocytes. Cytokine 39: 147-156.

6. Rautemaa, R., A. Jarvensivu, K. Kari, J. Wahlgren, A. DeCarlo, M. Richardson, and T. Sorsa. 2004. Intracellular localization of Porphyromonas gingivalis thiol proteinase in periodontal tissues of chronic periodontitis patients. Oral Dis 10: 298-305.

7. Page, R.C., and H.E. Schroeder. 1976. Pathogenesis of inflammatory periodontal disease. A summary of current work. Lab Invest 34: $235-249$.

8. Gemmell, E., K. Yamazaki, and G.J. Seymour. 2007. The role of T cells in periodontal disease: homeostasis and autoimmunity. Periodontol 2000 43: 14-40.

9. Taubman, M.A., and T. Kawai. 2001. Involvement of T-lymphocytes in periodontal disease and in direct and indirect induction of bone resorption. Crit Rev Oral Biol Med 12: 125-135.

10. Gaffen, S.L., and G. Hajishengallis. 2008. A new inflammatory cytokine on the block: re-thinking periodontal disease and the Th1/ Th2 paradigm in the context of Th17 cells and IL-17. J Dent Res 87: 817-828.

11. Sato, K., A. Suematsu, K. Okamoto, A. Yamaguchi, Y. Morishita, Y. Kadono, S. Tanaka, T. Kodama, S. Akira, Y. Iwakura, D.J. Cua, and H. Takayanagi. 2006. Th17 functions as an osteoclastogenic helper $\mathrm{T}$ cell subset that links $\mathrm{T}$ cell activation and bone destruction. J Exp Med 203: 2673-2682.

12. Lerner, U.H. 2006. Inflammation-induced bone remodeling in periodontal disease and the influence of post-menopausal osteoporosis. J Dent Res 85: 596-607.

13. Kong, Y.Y., W.J. Boyle, and J.M. Penninger. 1999. Osteoprotegerin ligand: a common link between osteoclastogenesis, lymph node formation and lymphocyte development. Immunol Cell Biol 77: $188-193$.

14. Udagawa, N., N. Takahashi, E. Jimi, K. Matsuzaki, T. Tsurukai, K. Itoh, N. Nakagawa, H. Yasuda, M. Goto, E. Tsuda, K. Higashio, M.T. Gillespie, T.J. Martin, and T. Suda. 1999. Osteoblasts/stromal cells stimulate osteoclast activation through expression of osteoclast differentiation factor/RANKL but not macrophage colonystimulating factor: receptor activator of NF-kappa B ligand. Bone 25: 517-523.

15. Simonet, W.S., D.L. Lacey, C.R. Dunstan, M. Kelley, M.S. Chang, R. Luthy, H.Q. Nguyen, S. Wooden, L. Bennett, T. Boone, G. Shimamoto, M. DeRose, R. Elliott, A. Colombero, H.L. Tan, G. Trail, J. Sullivan, E. Davy, N. Bucay, L. Renshaw-Gegg, T.M. Hughes, D. Hill, W. Pattison, P. Campbell, S. Sander, G. Van, J. Tarpley, P. Derby, R. Lee, and W.J. Boyle. 1997. Osteoprotegerin: a novel secreted protein involved in the regulation of bone density. Cell 89: 309-319.

16. Bostanci, N., T. Ilgenli, G. Emingil, B. Afacan, B. Han, H. Toz, G. Atilla, F.J. Hughes, and G.N. Belibasakis. 2007. Gingival crevicular fluid levels of RANKL and OPG in periodontal diseases: implications of their relative ratio. J Clin Periodontol 34: 370-376.

17. Bostanci, N., T. Ilgenli, G. Emingil, B. Afacan, B. Han, H. Toz, A. Berdeli, G. Atilla, I.J. McKay, F.J. Hughes, and G.N. Belibasakis. 2007. Differential expression of receptor activator of nuclear factor-kappaB ligand and osteoprotegerin mRNA in periodontal diseases. J Periodontal Res 42: 287-293.

18. Belibasakis, G.N., N. Bostanci, A. Hashim, A. Johansson, J. Aduse-Opoku, M.A. Curtis, and F.J. Hughes. 2007. Regulation of RANKL and OPG gene expression in human gingival fibroblasts and periodontal ligament cells by Porphyromonas gingivalis: a putative role of the Arg-gingipains. Microb Pathog 43: 46-53.

19. Reddi, D., N. Bostanci, A. Hashim, J. Aduse-Opoku, M.A. Curtis, F.J. Hughes, and G.N. Belibasakis. 2008. Porphyromonas gingivalis regulates the RANKL-OPG system in bone marrow stromal cells. Microbes Infect 10: 1459-1468.

20. Choi, B.K., S.Y. Moon, J.H. Cha, K.W. Kim, and Y.J. Yoo. 2005. Prostaglandin E(2) is a main mediator in receptor activator of nuclear factor-kappaB ligand-dependent osteoclastogenesis induced by Porphyromonas gingivalis, Treponema denticola, and Treponema socranskii. J Periodontol 76: 813-820.

21. Okahashi, N., H. Inaba, I. Nakagawa, T. Yamamura, M. Kuboniwa, K. Nakayama, S. Hamada, and A. Amano. 2004. Porphyromonas gingivalis induces receptor activator of NF-kappaB ligand expression in osteoblasts through the activator protein 1 pathway. Infect Immun 72: 1706-1714.

22. Gemmell, E., P.S. Bird, J.J. Bowman, L. Xu, B. Polak, L.J. Walsh, and G.J. Seymour. 1997. Immunohistological study of lesions induced by Porphyromonas gingivalis in a murine model. Oral Microbiol Immunol 12: 288-297.

23. Gemmell, E., T.A. Winning, P.S. Bird, and G.J. Seymour. 1998. Cytokine profiles of lesional and splenic T cells in Porphyromonas gingivalis infection in a murine model. J Periodontol 69: 1131-1138.

24. Baker, P.J., J. Garneau, L. Howe, and D.C. Roopenian. 2001. T-cell contributions to alveolar bone loss in response to oral infection with Porphyromonas gingivalis. Acta Odontol Scand 59: 222-225.

25. Stashenko, P., R.B. Goncalves, B. Lipkin, A. Ficarelli, H. Sasaki, and A. Campos-Neto. 2007. Th1 immune response promotes severe bone resorption caused by Porphyromonas gingivalis. Am J Pathol 170: 203-213. 
26. Bostanci, N., D. Reddi, M. Rangarajan, M.A. Curtis, and G.N. Belibasakis. 2009. Porphyromonas gingivalis stimulates TACE production by T cells. Oral Microbiol Immunol 24: 146-151.

27. Lum, L., B.R. Wong, R. Josien, J.D. Becherer, H. ErdjumentBromage, J. Schlondorff, P. Tempst, Y. Choi, and C.P. Blobel. 1999. Evidence for a role of a tumor necrosis factor-alpha (TNFalpha)-converting enzyme-like protease in shedding of TRANCE, a TNF family member involved in osteoclastogenesis and dendritic cell survival. J Biol Chem 274: 13613-13618.

28. Belibasakis, G.N., M. Brage, T. Lagergard, and A. Johansson. 2008. Cytolethal distending toxin upregulates RANKL expression in Jurkat T-cells. APMIS 116: 499-506.

29. Chakravarti, A., A.A. Marceau, L. Flamand, and P.E. Poubelle. 2008. Normal human primary CD4+ T lymphocytes synthesize and release functional osteoprotegerin in vitro. Lab Invest 88: 171-184.

30. Raisz, L.G. 1990. The role of prostaglandins in the local regulation of bone metabolism. Prog Clin Biol Res 332: 195-203.

31. Offenbacher, S., B.M. Odle, and T.E. Van Dyke. 1986. The use of crevicular fluid prostaglandin E2 levels as a predictor of periodontal attachment loss. J Periodontal Res 21: 101-112.

32. Noguchi, K., and I. Ishikawa. 2007. The roles of cyclooxygenase-2 and prostaglandin E2 in periodontal disease. Periodontol 2000 43: 85-101.

33. Schafer, D., M. Schmid, U.C. Gode, and H.W. Baenkler. 1999. Dynamics of eicosanoids in peripheral blood cells during bronchial provocation in aspirin-intolerant asthmatics. Eur Respir J 13: 638-646.

34. Futagami, S., T. Hiratsuka, A. Tatsuguchi, K. Suzuki, M. Kusunoki, Y. Shinji, K. Shinoki, T. Iizumi, T. Akamatsu, H Nishigaki, K. Wada, K. Miyake, K. Gudis, T. Tsukui, and C. Sakamoto. 2003. Monocyte chemoattractant protein 1 (MCP-1) released from Helicobacter pylori-stimulated gastric epithelial cells induces cyclooxygenase 2 expression and activation in T cells. Gut 52: $1257-1264$

35. Burgermeister, E., J. Endl, and W.V. Scheuer. 2003. Activation of cytosolic phospholipase A2 in human T-lymphocytes involves inhibitor-kappaB and mitogen-activated protein kinases. Eur $J$ Pharmacol 466: 169-180.

36. Steffen, M.J., S.C. Holt, and J.L. Ebersole. 2000. Porphyromonas gingivalis induction of mediator and cytokine secretion by human gingival fibroblasts. Oral Microbiol Immunol 15: 172-180.

37. Bodet, C., F. Chandad, and D. Grenier. 2006. Inflammatory responses of a macrophage/epithelial cell co-culture model to mono and mixed infections with Porphyromonas gingivalis, Treponema denticola, and Tannerella forsythia. Microbes Infect 8: 27-35.

38. Bodet, C., F. Chandad, and D. Grenier. 2006. Porphyromonas gingivalis-induced inflammatory mediator profile in an ex vivo human whole blood model. Clin Exp Immunol 143: 50-57. 